\title{
Plasmin Deficiency in Alzheimer's Disease Brains: Causal or Casual?
}

\author{
Carlos G. Dotti Cristian Galvan Maria Dolores Ledesma \\ Cavalieri Ottolenghi Scientific Institute, Fondazione Cavalieri Ottolenghi, Università degli Studi di Torino, \\ AO San Luigi Gonzaga, Orbassano, Italy
}

\section{Key Words}

Alzheimer's disease - Plasmin • Rafts • Cholesterol • Amyloid peptide

\begin{abstract}
Substantial recent evidence suggests that defects in amyloid peptide degradation can be at the base of cases of sporadic Alzheimer's disease (AD). Among the discovered brain enzymes with the capacity to degrade amyloid peptide, the serine protease plasmin acquires special physiological relevance because of its low levels in areas of $A D$ human brains with a high susceptibility to amyloid plaque accumulation. In this article we comment on a series of observations supporting the fact that plasmin paucity in the brain is not simply a secondary event in the disease but rather a primary defect in certain cases of sporadic AD. We also refer to recent data pointing to alterations in raft membrane domains and diminished membrane cholesterol as the underlying cause. Finally, we discuss the possibility that plasmin deficiency in the brain could lead to AD symptomatology because of amyloid aggregation and the triggering of cell death signaling cascades.
\end{abstract}

\section{KARGER}

Fax +41613061234

E-Mail karger@karger.ch

www. karger.com
(C) 2004 S. Karger AG, Basel

1660-2854/04/0015-0205\$21.00/0

Accessible online at:

www. karger.com/ndd

\section{Amyloid Peptide Aggregation in Alzheimer's Disease: More Peptide Production versus Less Degradation}

Alzheimer's disease (AD) is the most common neurodegenerative disorder in western societies, affecting up to 15 million individuals worldwide. It leads to death after a progressive memory deficit, cognitive impairment and personality changes accompanied by the appearance of two pathological hallmarks in specific brain areas: neurofibrillary tangles and amyloid plaques. Neurofibrillary tangles are intracellular filaments formed by the hyperphosphorylated Tau protein. Amyloid plaques are accumulations in the extracellular space of a $4-\mathrm{kD}$ peptide, $\mathrm{A} \beta$, derived from the processing of the transmembrane protein amyloid precursor protein (APP) [1].

Studies from different disciplines, from genetics to biochemistry, have helped to establish that amyloid plaques can form through different mechanisms. Thus, mutations in APP or in proteins involved in its cleavage result in an increased production of $A \beta$ peptide [2]. People bearing such mutations develop amyloid aggregates early in life, constituting the group of what is called early-onset or familial $\mathrm{AD}$ that represents less than $5 \%$ of $\mathrm{AD}$ cases. These findings, together with the numerous studies, both
Maria Dolores Ledesma

Cavalieri Ottolenghi Scientific Institute

AO San Luigi Gonzaga, Regione Gonzole 10

IT-10043 Orbassano, Torino (Italy)

Tel.+39011670 5482, Fax +39011670 5449, E-Mail lola.ledesma@unito.it 
in vivo and in cells in culture, that showed how toxic these aggregates are to neuronal viability and function [3], are the basis for the 'amyloidogenic' concept of this disease pathogenesis. Different from mutations that directly affect APP cleavage, the inheritance of the $\varepsilon 4$ allele of the apolipoprotein E (ApoE) predisposes to abnormal amyloid accumulation and constitutes a risk factor although not a determinant for the appearance of late-onset or sporadic $A D$ [4]. It remains unclear how this allele affects amyloid production but the fact that ApoE is involved in cholesterol homeostasis supports the view that defective metabolism and/or transport of this lipid could be the cause. This concept has been later reinforced by biochemical and retrospective clinical studies [5, 6] (see below). In addition, recent observations in cells in culture indicate that alterations in cholesterol metabolism and transport affect the organization of cholesterol-rich membrane microdomains, the so-called rafts, which in the end could determine anomalous APP processing [7, 8].

In addition to excess production, it has been reasoned that amyloid aggregates can develop because of a failure in the amyloid peptide clearance systems due to age-related downregulation. The presence in the brain of numerous enzymes with an amyloid peptide-degrading capacity, such as neprilysin, insulin-degrading enzyme (IDE), matrix metalloproteinase 9, endothelin-converting enzyme, elastase and the serine protease plasmin [9], supports the importance of proper degradation to maintain the physiological steady-state levels of the peptide. In certain cases, like for IDE, a genetic association with some AD populations has been reported [10]. Recent studies showing the low ability to degrade exogenous $A \beta$ or higher accumulation of the endogenous peptide in brains of mice lacking neprilysin [11], endothelin-converting enzyme [12], IDE [13] or plasmin [14] highlight the importance of clearance mechanisms to avoid amyloid accumulation in vivo. That similar clearance defects could underlie the human disease scenario is suggested by recent work showing that the brains of a group of AD patients present low levels of plasmin in the same areas where amyloid aggregates most commonly form [15].

Although many other alterations have been proposed to contribute to aberrant amyloid aggregation and $\mathrm{AD}$, among them the presence of certain metals in the extracellular milieu or the lack of trophic factors [16], in this article we only refer to the possible linkage between $\mathrm{AD}$ and defects in the brain plasminogen-plasmin system.

\section{The Brain Plasminogen System}

The plasminogen system is composed of an inactive proenzyme, plasminogen, which upon binding to the cellular surface is cleaved to the active protease plasmin. The plasmin proteolytic cascade is tightly regulated by the presence of two types of activators: tissue-type plasminogen activator (tPA) and urokinase-type plasminogen activator (UPA), and several inhibitors: plasminogen activator inhibitors (PAI1, PAI2, etc.) and plasmin inhibitors $(\alpha$-2-antiplasmin and $\alpha$-2-macroglobulin) [17]. This system was first described in blood where it plays a role in the clearance of fibrin clots. It also exists in brain where tPA is the main plasminogen activator and is widely expressed in the hippocampus, hypothalamus, cerebellum, and amygdala [18]. Interestingly, fibrin has not been found in the brain, indicating that the plasminogen system has other functions than that of coagulation inhibitor. Indeed, substantial evidence now suggests that the brain tPA/plasminogen cascade is important for proper extracellular matrix degradation during neuronal development [19] and for events that require synaptic plasticity such as long-term potentiation [20], memory [21] and motor learning [22]. Plasminogen is potentially the most likely substrate for tPA. Yet, the contribution to the generation of plasmin from plasminogen is not the sole function of tPA. In fact, tPA plays a plasmin-independent role in microglial activation [23], mossy fiber outgrowth stimulation [24] and in the enhancement of NMDA receptormediated signaling [25].

In addition to its physiological functions, an increase of tPA and/or plasmin production has been involved in neuronal death in certain pathologies such as seizure and stroke $[26,27]$. In ischemia and excitotoxicity models, neurotoxicity is mediated by increased tPA synthesis followed by plasmin generation leading to laminin degradation $[27,28]$. On the other hand, tPA plasmin-independent effects seem to mediate the neuronal death that occurs after stroke [29].

Recent evidence suggests that the plasminogen system may also play a key role in AD pathogenesis. This is supported by the demonstration that plasmin can efficiently degrade the amyloid peptide in vitro $[30,31]$ and that the degradation of $A \beta$ aggregates in the brain, after injection of the peptide, is significantly less efficient in tPA or plasminogen knockout mice [14], a result consistent with our own observations that brain plasmin levels are significantly reduced in a relevant percentage of AD cases [15]. Moreover, the finding that the amyloid peptide induces tPA and uPA expression [30], and that the addition of

\footnotetext{
$\overline{206} \quad$ Neurodegenerative Dis 2004;1:205-212
} 
exogenous tPA, uPA and plasminogen to cell cultures reduces $A \beta$ neurotoxicity $[32,33]$ suggests that changes in tPA or UPA can per se play a role in AD pathology. All these observations have set the basis for the hypothesis that a defect in the brain plasminogen system could be a major cause of $\mathrm{AD}$ pathogenesis.

\section{Low Brain Plasmin in AD Is Not Due to Downregulation of Plasminogen-Binding or Activating Molecules}

In an attempt to understand the possible causes for the reduced plasmin levels in certain $\mathrm{AD}$ brains we measured the amount of its precursor, plasminogen, in AD and nonAD human brains [15]. This approach revealed that total plasminogen levels are not altered in AD brains, despite the low levels of plasmin, suggesting that disease-associated features such as inflammation or cell death are not responsible for plasmin paucity. Yet, plasminogen activation to plasmin not only depends on the levels of the precursor but also on its binding to the cell surface. In fact, the analysis of the amount of plasminogen bound to membranes derived from low plasmin brains revealed a striking reduction. In a functional assay we also observed that the ability of these membranes to bind and activate exogenous plasminogen was clearly reduced [15].

Binding of plasminogen takes place through different binding molecules, among them the ganglioside GM1, and the C-terminal lysine-containing proteins annexin, amphoterin, and $\alpha$-enolase [17]. Once bound to the membrane via these molecules, tPA and uPA can exert the cleavage-activating role. Thus, low plasmin in the AD brains may be the result of decreased levels of any of these plasminogen membrane-binding and/or activating molecules. Biochemical measurements in the human brain samples with low or normal plasmin revealed that neither the levels of plasminogen-activating nor plasminogen membrane-binding molecules are significantly affected in the cases with low plasmin. These results led us to argue that low plasminogen binding, and thus low plasmin levels and activity, may be due to a defect in the plasma membrane itself, most likely in the domains where binding occurs.

Previous studies in our laboratory demonstrated that the plasma membrane domains responsible for plasminogen binding and activation are the raft domains [34]. These are detergent-insoluble complexes enriched in cholesterol and sphingolipids [35]. They are involved in essential cellular functions such as protein sorting and sig- naling [36]. In a proteomic-based study of rafts purified from neurons in culture, we found the enrichment of all the above-mentioned plasminogen-binding molecules in these domains ( $\alpha$-enolase, amphoterin, annexin and GM1). In addition, we confirmed the ability of these molecules to bind plasminogen in neuronal cultures. In agreement with these findings, we showed that plasmin almost exclusively forms in the raft fraction of primary neurons, and that diminished levels of both membrane-bound plasminogen and plasmin occur in neurons with reduced membrane cholesterol and therefore altered rafts [34]. The importance of rafts in plasminogen activation justified the study of raft organization in $\mathrm{AD}$ cases with low plasmin. This study seemed to us relevant because, besides their contribution to the plasminogen system regulation, other evidence has pointed to a role of brain cholesterol and rafts in amyloid production. These are reviewed below.

\section{Cholesterol, Rafts and AD}

As mentioned before, the involvement of cholesterol in $\mathrm{AD}$ was suggested in work done a decade ago, when the existence of a genetic link between late-onset $\mathrm{AD}$ and the ApoE4, a protein involved in cholesterol homeostasis, was shown [4]. Recently, the relevance of brain cholesterol was stressed by retrospective clinical studies showing that patients with elevated serum cholesterol levels treated with blood cholesterol-lowering drugs, such as statins, present a decreased incidence of $\mathrm{AD}[5,6]$. In addition, experiments with cells in culture showed that acute removal of membrane cholesterol results in less $A \beta$ production [7, 8, 37]. This evidence has led to the idea that high cholesterol may contribute to $\mathrm{A} \beta$ aggregation in $\mathrm{AD}$ because it encourages the generation of the amyloid peptide.

In contrast, a number of observations point to low brain cholesterol as a risk factor for neurodegeneration, and also for AD. In the genetic disorder RSH/Smith-Lemli-Opitz syndrome the accumulation of 7-dehydrocholesterol and the paucity of cholesterol are thought to be responsible for neurodegeneration and early death [38]. Importantly, the gene responsible for this disease is homologous to seladin-1, which is abnormally downregulated in the neurons of patients with AD in the areas of the brain which show the highest levels of amyloid deposition $[39,40]$. One interpretation of these results would be that low cholesterol in these neurons might lead to higher amyloid production or lower degradation. Animal studies 
have not added much light to whether high brain cholesterol does or does not encourage amyloid aggregation. While Fassbender et al. [37] reported a decrease in $A \beta$ levels in the CSF and brain homogenates of guinea pigs treated with high doses of sinvastatin, a cholesterol synthesis inhibitor, Park et al. [41] described an enhancement of amyloid production and senile plaque deposition in the brains of female mice treated with another cholesterol synthesis inhibitor, lovastatin. Observations made in mice bearing a defect in cholesterol homeostasis due to mutations in the NPC1 gene responsible for the Niemann-Pick disease type C (NPC) are in agreement with the latter. In NPC cells cholesterol accumulates in late endosomes and lysosomes, but the anterograde transport of the lipid to the axonal membrane is reduced [42]. Interestingly, an enhanced generation of amyloid peptide, like in $\mathrm{AD}$, has been reported in this disease [43].

Given all the above, at times contradictory, information the question remains whether low brain cholesterol is beneficial or deleterious. One way to address this issue is to better understand the mechanism/s by which cholesterol regulates amyloid production and/or degradation. The reported presence of APP, and its $\beta$ and $\gamma$ secretases in rafts of overexpressing cells [8, 43] supports the notion that cholesterol-rich membrane rafts play a role in amyloid peptide generation, but how exactly they participate is rather, if not totally, unclear. It has been proposed that rafts are the places where, upon endocytosis, APP and its secretases get in contact [8]. Yet, the results supporting this conclusion derive from experiments based on viralmediated overexpression in nonneuronal cells or undifferentiated neuronal cell lines, raising concern about their physiological validity. To overcome this limitation, we have recently investigated whether raft organization and composition are affected in human brains, comparing AD brains showing diminished plasminogen binding and activation to plasmin, an event that is raft-dependent, with normal plasmin AD cases and with brains of age-matched control individuals.

\section{Low Plasmin in AD Brains Is Due to Low Membrane Cholesterol and Disorganized Rafts}

As described earlier, the observation that the levels of expression of plasminogen-binding and activating molecules are not altered in the low plasmin AD cases and that plasmin generation occurs in raft membrane domains led us to the hypothesis that changes in rafts could be respon- sible for the defect. We did confirm this hypothesis in a biochemical analysis that revealed a specific and significant reduction in protein content in the $\mathrm{AD}$ low plasmin raft fractions compared to raft fractions of age-matched control individuals or AD patients with normal levels of the protease [15]. The fact that the protein content in nonraft membrane fractions was similar in all brain groups and that all AD brains analyzed, with low or normal plasmin levels, showed a comparable degree of neurodegeneration, argues against neuronal loss being responsible for the low protein content found in the raft fractions from AD low plasmin brains only. Importantly, this alteration was evident in brain areas severely affected in the disease such as the hippocampus but not significant in those with low amyloid plaque content like the cerebellum (fig. 1). The changes in raft organization affected the membrane distribution of plasminogen-binding and activating molecules such as GM1 or uPA receptor. Given that cholester$\mathrm{ol}$ is a main component of rafts it was reasonable to postulate that the defects observed were the consequence of the paucity of cholesterol. Indeed, while no differences were found in total cholesterol levels, membrane cholesterol showed a moderate, still significant, reduction of around $30 \%$ in the low plasmin hippocampi with disorganized rafts [15]. Membrane cholesterol measurement in the cerebellum, a relatively unaffected area in AD that did not show significant raft alterations, revealed a reduction not higher than 19\% [Ledesma and Dotti, unpubl. observations]. These results support the tendency to lose membrane cholesterol in these brains but suggest that certain areas are more sensitive than others. This could explain why these areas are particularly affected by the disease. Moreover, these observations suggest that a cholesterol loss greater than $19 \%$ would be necessary to alter rafts and raft-mediated functions.

To test if the membrane changes observed in the AD patients' hippocampi could be at the base of the plasmin paucity we performed experiments in rodent hippocampal neurons in culture. When these cells were subjected to a chronic treatment with cholesterol-reducing drugs, until obtaining a 30\% membrane cholesterol reduction similar to that detected in the AD hippocampi, we observed alterations in raft organization, and 59 and $49 \%$ reduction in plasminogen binding and plasmin generation, respectively [15]. Plasminogen binding and activation depend on cholesterol levels in a dose-dependent manner as a more drastic reduction of this lipid from hippocampal neurons, up to $60 \%$, resulted in the almost complete inhibition of these events [34]. We conclude therefore that membrane cholesterol levels and raft integrity are essential to war- 


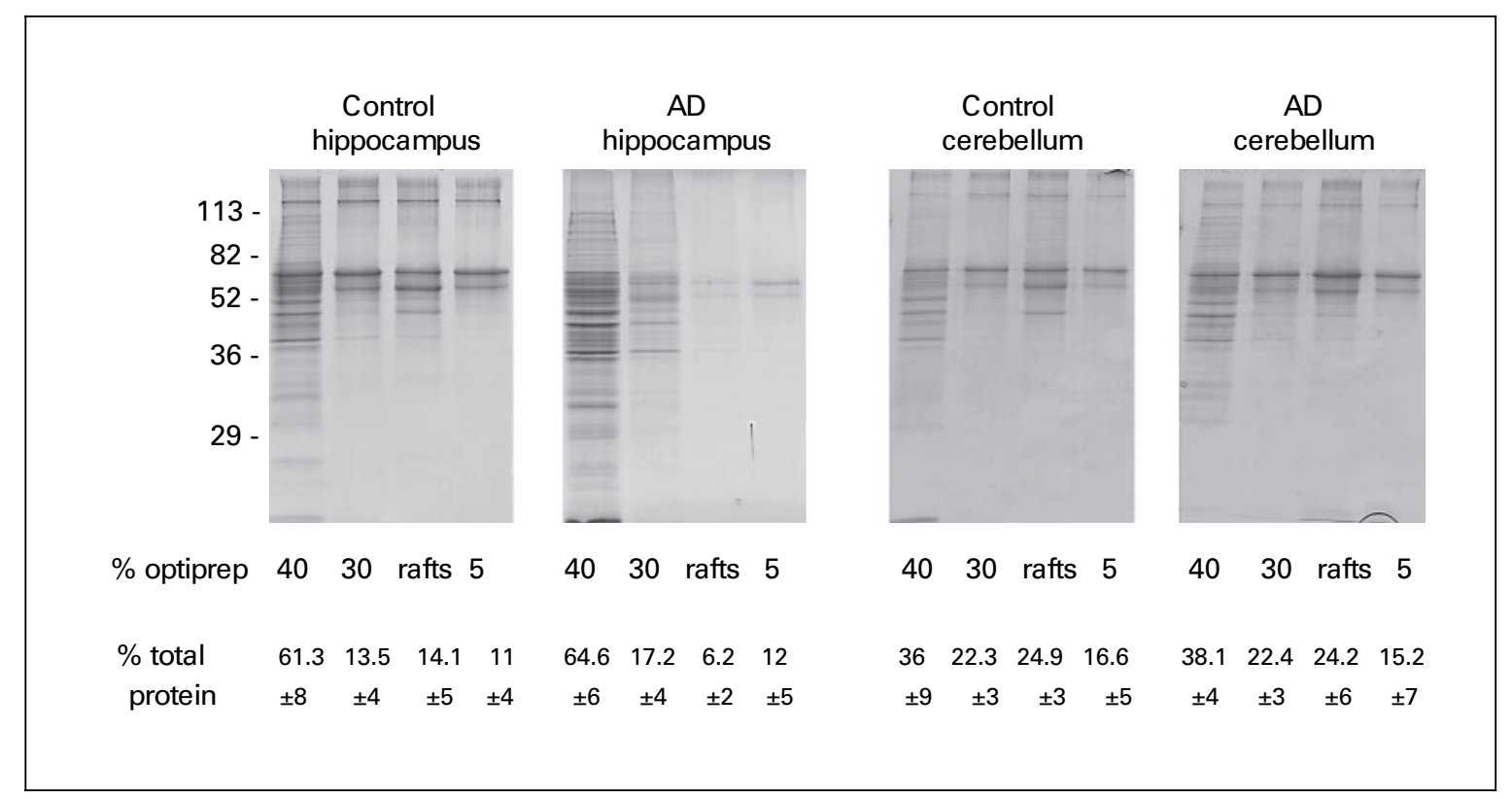

Fig. 1. Altered rafts in specific brain areas of $A D$ brains with low plasmin. Rafts were isolated from hippocampal or cerebellar human membranes upon extraction in $1 \%$ Triton X-100 on ice of an equal amount of total protein $(100 \mu \mathrm{g})$ and flotation in Optiprep gradients. The integrity of rafts (fractions corresponding to the interphase 30 $5 \%$ Optiprep) was monitored by the amount of proteins visualized by SDS-PAGE and Coomassie blue staining. The image shows representative examples for control individuals with normal levels of plasmin and AD patients with low plasmin in the hippocampus. Numbers on the left indicate molecular weights. While the amount of proteins in rafts is very similar in the cerebellum of control and $\mathrm{AD}$ individuals ( $24.9 \pm 3$ and $24.2 \pm 6 \%$, respectively), the protein content in the raft fraction of $\mathrm{AD}$ low plasmin hippocampi $(6.2 \pm 2 \%)$ is significantly diminished with respect to the hippocampal raft fractions of control individuals $(14.1 \pm 2 \%)$. This cannot be attributed to the diminished amount of total protein due to neuronal loss in the $\mathrm{AD}$ low plasmin hippocampi as the loss of protein in the raft fraction is accompanied by a concomitant increase in fractions 40 and $30 \%$ Optiprep. This is quantified in the lower panel that shows the mean values with standard deviations of the percentage of total protein in each fraction of the gradient resulting from the analysis of 10 samples from each group. These results also show the existence of susceptibility differences between cellular populations, which could explain the distribution of the pathological features in AD brains. rant the functionality of one of the mechanism involved in amyloid degradation.

Besides inefficient amyloid degradation, plasmin paucity in the brain could lead to other deleterious effects. We envision that compensatory mechanisms would be triggered to produce more plasmin. One of them could rely on increased tPA or UPA production. The involvement of both molecules in cell signaling raises concern about an excessive activation of signaling cascades. In this regard, and although the mechanisms are not yet clear, a plasmin-independent role for tPA in neuronal death has been described in stroke [28].

\section{Low Membrane Cholesterol, Altered Rafts and ApoE4: Is There a Link?}

An interesting observation made in the biochemical analysis of the human hippocampi was that while most of the AD patients showed reduced plasmin levels with respect to control individuals a group of AD brains contains normal levels of the protease. Accordingly, this last $\mathrm{AD}$ group did not show membrane raft alterations or reduced levels of membrane cholesterol [15]. These differences in the AD samples could not be correlated with the amount of amyloid plaques and Tau filament aggregation or with variables such as age, sex, postmortem brain sampling delay, hippocampal area analyzed, degree of dementia or cause of death. The only correlation we observed was the presence of the ApoE4 in AD brains with low plasmin and altered rafts and membrane cholesterol while $\mathrm{AD}$ 
Fig. 2. Model for the involvement of the plasminogen system in amyloid accumulation and $\mathrm{AD}$. In physiological conditions plasminogen binds to the neuronal surface through specific binding molecules. Upon binding it can be cleaved and activated to the protease plasmin by activating enzymes like tPA or uPA. The process of binding and activation takes place specifically in raft membrane domains. Plasmin production would contribute to the clearance of the amyloid peptide maintaining the peptide amount at physiological steady-state levels. By contrast, in certain AD cases rafts are disorganized due to low levels of membrane cholesterol. This would alter the distribution of plasminogen-binding and activating molecules resulting in impaired plasminogen binding to the membrane and thus low plasmin production. A consequence of plasmin paucity is the inefficient amyloid peptide degradation. This defect, over the years, would contribute to amyloid plaque formation, a pathological hallmark in $\mathrm{AD}$ brains.
PLASMINOGEN SYSTEM

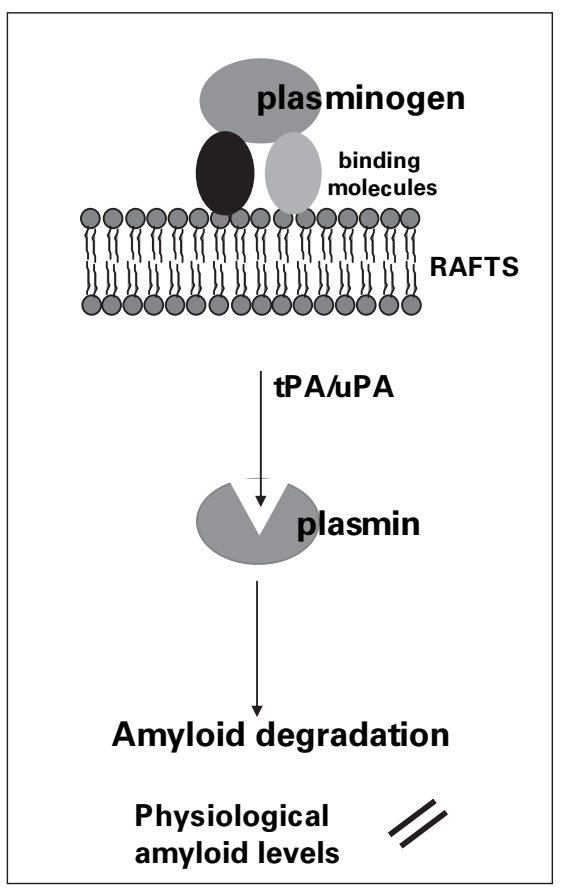

PLASMINOGEN SYSTEM IN AD

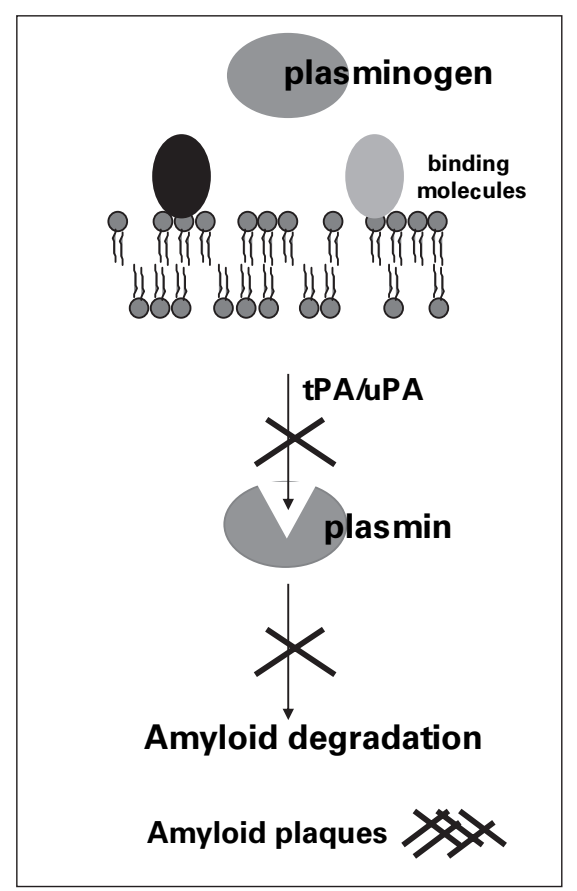

brains without these alterations bore the $\varepsilon 2$ or $\varepsilon 3$ alleles. Although to confirm this correlation a study with a larger population is needed, it points to a link between ApoE4, a protein involved in cholesterol homeostasis that is a risk factor for $\mathrm{AD}$, and membrane raft cholesterol deficiencies.

It is not known how the ApoE4 could determine cholesterol loss of brain cells. One explanation could be the finding that astrocytes from ApoE4-derived mice are less efficient in providing cholesterol to neurons than those from ApoE3-derived ones [44]. Another interesting possibility is that of increased oxidative stress in an ApoE4 background as suggested by the higher capacity to produce nitric oxide of ApoE4 mice microglia compared to that from ApoE3 mice [45]. This could in turn promote cholesterol oxidation that could affect raft organization and functions. Still, the question remains as to why not all ApoE4 bearers develop the disease. It is possible that nonAD ApoE4 individuals are protected by environmental or genetic factors, which make the provision of cholesterol from the astrocytes to the neurons more efficient, or make rafts more resistant to low levels or oxidation of cholesterol, or increase the activity of other amyloid-degrading enzymes. These possibilities need to be experimentally addressed.

\section{Conclusions and Perspectives}

The causes for sporadic or late-onset AD that represents the vast majority of AD cases are not firmly established. Our data support the view that in certain AD patients a chronically occurring loss of neuronal membrane cholesterol could lead to defects in raft organization that, among other deficits, would result in the low production of plasmin, and consequently in a deficient plasminmediated amyloid degradation contributing to amyloid peptide aggregation. This model is summarized in figure 2.

We believe that the data presented above contribute to clarifying how neuronal membrane cholesterol and rafts may relate to AD pathogenesis. Also important is the fact that the data point in the direction that the risk component associated with the presence of the ApoE4 allele is the paucity of cholesterol and disorganized rafts in the neuronal membrane. If this turns out to be correct in future and independent studies it is possible that drugs that protect against such loss could prevent the appearance of the disease or slow down its course. On the other hand, our observations indicate the importance of the plasminogen system as a target for favoring amyloid degradation. Many ways to enhance plasmin activity could 
be explored, among them the use of specific plasminogen activators. In this regard, it is interesting to mention that tPA is an approved drug for use in humans that has already been applied for the treatment of stroke.

\section{Acknowledgments}

We are grateful for the financial support of the EU grant DIADEM (QLK-3-CT-2001-02362) to C.G.D and M.D.L. that has made this work possible.

\section{References}

$>1$ Selkoe DJ: Alzheimers' disease: Genes, proteins, and therapy. Physiol Rev 2001;81:741766.

2 Price DL, Sisodia SS: Mutant genes in familial Alzheimer's disease and transgenic models. Annu Rev Neurosci 1998;21:479-505.

3 Small DH, Mok SS, Bornstein JC: Alzheimer's disease and Abeta toxicity: From top to bottom. Nat Rev Neurosci 2001;2:595-598.

$\checkmark 4$ Corder EH, Saunders AM, Strittmatter WJ, Schmechel DE, Gaskell PC, Small GW, Roses AD, Haines JL, Pericak-Vance MA: Gene dose of apolipoprotein $\mathrm{E}$ type 4 allele and the risk of Alzheimer's disease in late onset families. Science 1993;261:921-923.

$>5$ Wolozin B, Kellman W, Ruosseau P, Celesia GG, Siegel G: Decreased prevalence of Alzheimer disease associated with 3-hydroxy-3methyglutaryl coenzyme A reductase inhibitors. Arch Neurol 2000;57:1439-1443.

6 Jick H, Zornberg GL, Jick SS, Seshadri S, Drachman DA: Statins and the risk of dementia. Lancet 2000;356:1627-1631

7 Simons M, Keller P, De Strooper B, Beyreuther K, Dotti CG, Simons K: Cholesterol depletion inhibits the generation of beta-amyloid in hippocampal neurons. Proc Natl Acad Sci USA 1998;95:6460-6464.

$\checkmark 8$ Ehehalt R, Keller P, Haass C, Thiele C, Simons $\mathrm{K}$ : Amyloidogenic processing of the Alzheimer beta-amyloid precursor protein depends on lipid rafts. J Cell Biol 2003;160:113-123.

$\checkmark 9$ Selkoe DJ: Clearing the brain's amyloid cobwebs. Neuron 2001;32:177-180.

$\checkmark 10$ Bertram L, Blacker D, Mullin K, Keeney D, Jones J, Basu S, Yhu S, McInnis MG, Go RC, Vekrellis K, Selkoe DJ, Saunders AJ, Tanzi RE: Evidence for genetic linkage of Alzheimer's disease to chromosome 10q. Science 2000;290:2302-2303.

-11 Iwata N, Tsubuki S, Takaki Y, Shirotani K, Lu B, Gerard NP, Gerard C, Hama E, Lee HJ, Saido TC: Metabolic regulation of brain Abeta by neprilysin. Science 2001;292:1550-1552.

-12 Eckman EA, Watson M, Marlow L, Sambamurti K, Eckman CB: Alzheimer's disease beta-amyloid peptide is increased in mice deficient in endothelin-converting enzyme. $\mathrm{J}$ Biol Chem 2003;278:2081-2084

$\checkmark 13$ Farris W, Mansourian S, Chang Y, Lindsley L, Eckman EA, Frosch MP, Eckman CB, Tanzi RE, Selkoe DJ, Guenette S: Insulin-degrading enzyme regulates the levels of insulin, amyloid beta-protein, and the beta-amyloid precursor protein intracellular domain in vivo. Proc Natl Acad Sci USA 2003;100:4162-4167.
14 Melchor JP, Pawlak R, Strickland S: The tissue plasminogen activator-plasminogen proteolytic cascade accelerates amyloid-beta (Abeta) degradation and inhibits Abeta-induced neurodegeneration. J Neurosci 2003;23:88678871 .

15 Ledesma MD, Abad-Rodriguez J, Galvan C, Biondi E, Navarro P, Delacourte A, Dingwall C, Dotti CG: Raft disorganization leads to reduced plasmin activity in Alzheimer's disease brains. EMBO Rep 2003;4:1190-1196.

16 Bush AI: The metallobiology of Alzheimer's disease. Trends Neurosci 2003;26:207-214.

17 Collen D: The plasminogen (fibrinolytic) system. Thromb Haemost 1999;82:259-270.

18 Sappino AP, Madani R, Huarte J, Belin D, Kiss JZ, Wohlwend A, Vassalli JD: Extracellular proteolysis in the adult murine brain. J Clin Invest 1993;92:679-685.

$>19$ Friedman GC, Seeds NW: Tissue plasminogen activator expression in the embryonic nervous system. Brain Res Dev Brain Res 1994;81:4149.

20 Madani R, Hulo S, Toni N, Madani H, Steimer T, Muller D, Vassalli JD: Enhanced hippocampal long-term potentiation and learning by increased neuronal expression of tissue-type plasminogen activator in transgenic mice. EMBO J 1999; 18:3007-3012.

21 Calabresi P, Napolitano M, Centonze D, Marfia GA, Gubellini P, Teule MA, Berretta N, Bernardi G, Frati L, Tolu M, Gulino A: Tissue plasminogen activator controls multiple forms of synaptic plasticity and memory. Eur J Neurosci 2000; 12:1002-1012.

22 Pawlak R, Nagai N, Urano T, NapiorkowskaPawlak D, Ihara H, Takada Y, Collen D, Takada A: Rapid, specific and active site-catalyzed effect of tissue-plasminogen activator on hippocampus-dependent learning in mice. Neuroscience 2002;113:995-1001.

23 Rogove AD, Siao C, Keyt B, Strickland S, Tsirka SE: Activation of microglia reveals a nonproteolytic cytokine function for tissue plasminogen activator in the central nervous system. J Cell Sci 1999;112:4007-4016.

24 Wu YP, Siao CJ, Lu W, Sung TC, Frohman MA, Milev P, Bugge TH, Degen JL, Levine JM, Margolis RU, Tsirka SE: The tissue plasminogen activator (tPA)/plasmin extracellular proteolytic system regulates seizure-induced hippocampal mossy fiber outgrowth through a proteoglycan substrate. J Cell Biol 2000;148: 1295-1304.
25 Nicole O, Docagne F, Ali C, Margaill I, Carmeliet $\mathrm{P}$, MacKenzie ET, Vivien D, Buisson A: The proteolytic activity of tissue-plasminogen activator enhances NMDA receptor-mediated signaling. Nat Med 2001;7:59-64.

26 Qian Z, Gilbert ME, Colicos MA, Kandel ER, Kuhl D: Tissue-plasminogen activator is induced as an immediate-early gene during seizure, kindling and long-term potentiation. Nature 1993;361:453-457.

27 Tsirka SE, Rogove AD, Strickland S: Neuronal cell death and tPA. Nature 1996;384:123-124.

28 Chen ZL, Strickland S: Neuronal death in the hippocampus is promoted by plasmin-catalyzed degradation of laminin. Cell 1997;91: 917-925.

29 Wang YF, Tsirka SE, Strickland S, Stieg PE, Soriano SG, Lipton SA: Tissue plasminogen activator (tPA) increases neuronal damage after focal cerebral ischemia in wild-type and tPA-deficient mice. Nat Med 1998;4:228-231.

30 Ledesma MD, Da Silva JS, Crassaerts K, Delacourte A, De Strooper B, Dotti CG: Brain plasmin enhances APP alpha-cleavage and Abeta degradation and is reduced in Alzheimer's disease brains. EMBO Rep 2000;1:530-535.

31 Tucker HM, Kihiko M, Caldwell JN, Wright S, Kawarabayashi T, Price D, Walker D, Scheff S, McGillis JP, Rydel RE, Estus S: The plasmin system is induced by and degrades amyloidbeta aggregates. J Neurosci 2000;20:39373946.

32 Tucker HM, Kihiko-Ehmann M, Wright S, Rydel RE, Estus S: Tissue plasminogen activator requires plasminogen to modulate amyloidbeta neurotoxicity and deposition. J Neurochem 2000;75:2172-2177.

33 Tucker HM, Kihiko-Ehmann M, Estus S: Urokinase-type plasminogen activator inhibits amyloid-beta neurotoxicity and fibrillogenesis via plasminogen. J Neurosci Res 2002;70:249_ 255.

34 Ledesma MD, Da Silva JS, Schevchenko A, Wilm M, Dotti CG: Proteomic characterisation of neuronal sphingolipid-cholesterol microdomains: Role in plasminogen activation. Brain Res 2003;987:107-116.

35 Simons K, Ikonen E: Functional rafts in cell membranes. Nature 1997;387:569-572.

36 Simons K, Toomre D: Lipid rafts and signal transduction. Nat Rev Mol Cell Biol 2000;1: 31-39. 
37 Fassbender K, Simons M, Bergmann C, Stroick M, Lutjohann D, Keller P, Runz H, Kuhl S, Bertsch $\mathrm{T}$, von Bergmann $\mathrm{K}$, Hennerici $\mathrm{M}$, Beyreuther K, Hartmann T: Simvastatin strongly reduces levels of Alzheimer's disease beta-amyloid peptides Abeta 42 and Abeta 40 in vitro and in vivo. Proc Natl Acad Sci USA 2001;98:5856-5861.

38 Porter FD: RSH/Smith-Lemli-Opitz syndrome: A multiple congenital anomaly/mental retardation syndrome due to an inborn error of cholesterol biosynthesis. Mol Genet Metab 2000;71:163-174.

39 Iivonen S, Hiltunen M, Alafuzoff I, Mannermaa A, Kerokoski P, Puolivali J, Salminen A, Helisalmi S, Soininen H: Seladin-1 transcription is linked to neuronal degeneration in Alzheimer's disease. Neuroscience 2002;113:301310 .
40 Greeve I, Hermans-Borgmeyer I, Brellinger C, Kasper D, Gomez-Isla T, Behl C, Levkau B, Nitsch RM: The human DIMINUTO/ DWARF1 homolog seladin-1 confers resistance to Alzheimer's disease-associated neurodegeneration and oxidative stress. J Neurosci 2000;20:7345-7352.

-41 Park IH, Hwang EM, Hong HS, Boo JH, Oh SS, Lee J, Jung MW, Bang OY, Kim SU, MookJung I: Lovastatin enhances Abeta production and senile plaque deposition in female $\mathrm{Tg} 2576$ mice. Neurobiol Aging 2003;24:637-643.
42 Karten B, Vance DE, Campenot RB, Vance JE: Cholesterol accumulates in cell bodies, but is decreased in distal axons, of Niemann-Pick C1deficient neurons. J Neurochem 2002;83: 1154-1163.

43 Burns M, Duff K: Cholesterol in Alzheimer's disease and tauopathy. Ann NY Acad Sci 2002; 977:367-375

44 Gong JS, Kobayashi M, Hayashi H, Zou K, Sawamura N, Fujita SC, Yanagisawa K, Michikawa M: Apolipoprotein E (ApoE) isoformdependent lipid release from astrocytes prepared from human ApoE3 and ApoE4 knockin mice. J Biol Chem 2002;277:29919-29926.

45 Colton CA, Brown CM, Cook D, Needham LK, $\mathrm{Xu}$ Q, Czapiga M, Saunders AM, Schmeche DE, Rasheed K, Vitek MP: APOE and the regulation of microglial nitric oxide production: A link between genetic risk and oxidative stress. Neurobiol Aging 2002;23:777-785. 